\title{
Botvervangende materialen
}

G.H. van Kralingen, Y. El-Massoudi, E.M.M. van Lieshout, P.Patka

Erasmus MC, Afdeling Heelkunde-Traumatologie, Rotterdam

Mevr. Drs. G.H. van Kralingen, medisch student

Dhr. Drs. Y. El-Massoudi, arts-onderzoeker

Mevr. Dr. E.M.M. van Lieshout, onderzoekscoördinator traumatologie

Dhr. Prof. Dr. P. Patka, traumachirurg

Trefwoorden:

Augmentatie, Botsubstitutie, Bottransplantaat, Calciumfosfaat, Hydroxyapatiet 
Correspondentie-adres:

Prof. Dr. P. Patka

Erasmus MC

Afdeling Heelkunde-Traumatologie

Postbus 2040

3000 CA Rotterdam

Tel. 010-7032395

Fax. 010-7032396

E-mail:p.patka@erasmusmc.nl 


\section{Samenvatting}

In de trauma en orthopedische chirurgie is het gebruik van een autogeen bottransplantaat voor het opvullen van botdefecten de therapie van eerste keus. Omdat er nadelen kleven aan het gebruik van autogeen bottransplantaat (morbiditeit van de donorplaats en beperkte hoeveelheid botweefsel) bestaat er een belangstelling voor de botvervangende materialen. Dit artikel biedt een overzicht van informatie over de botvervangende materialen. Voor optimale ingroei van bot bezit een transplantaat idealiter osteogene, osteoinductieve en osteoconductieve eigenschappen. Botvervangende materialen zijn voornamelijk osteoconductief en functioneren als een matrix voor botregeneratie. Poriegrootte, porositeit en kristaliniteit bepalen in belangrijke mate de osteoconductiviteit van het materiaal. Het meest onderzocht en ook het meest gebruikte botvervangende materiaal is calciumfosfaat. Daarnaast worden ook calciumsulfaten en bioactief glas gebruikt als botvervangend materiaal. Nieuwe ontwikkelingen als toevoegingen van groeifactoren aan botvervangende materialen worden nog onderzocht. 


\begin{abstract}
Bone substitutes - In trauma and orthopedic surgery the use of autograft is a first choice therapy for filling bone defects. Due to drawbacks in the use of autografts (for example donor site morbidity and limited amount of bone tissue) there is an increasing interest in the use of (artificial) bone substitutes. This article provides an overview of the basic science of bone substitution. For optimal ingrowth of bone a transplant should have osteogenic, osteoinductive and osteoconductive characteristics. Bone substitutes are mostly osteoconductive and provide a scaffold for bone regeneration.

Osteoconductivity is mainly determined by pore size, porosity and cristallinity. Calcium phosphates represent a group of bone substitutes that is being used mostly, and this group of products has been extensively studied. In addition, calcium sulphates and bioactive glass are used also. New developments such as the addition of growth factors to bone substitutes are under extensive research.
\end{abstract}




\section{Geschiedenis}

Het opvullen van botdefecten kent een lange geschiedenis. Al in de oudheid werden bottransplantaties uitgevoerd (1). De geschiedenis van de bottransplantatie begon in 1668. De Nederlander Job van Meek'ren beschreef hoe het schedeldak van een hond werd gebruikt om de schedel van een gewonde soldaat te herstellen. Het was een geslaagde operatie met een goede integratie van het transplantaat (2). De eerste autologe bottransplantatie werd in 1820 uitgevoerd door de Duitser Philips von Walter. De term bottransplantatie, 'greffe osseuse', werd voor het eerst gebruikt in een publicatie uit 1861 van Leopold Ollier uit Lyon (3).

Vanwege de nadelen die aan een autologe bottransplantatie verbonden zijn is in de jaren twintig het onderzoek naar de botvervangende materialen op gang gekomen. Sinds de ontdekking van calciumfosfaat cementen in de jaren tachtig is het aantal studies sterk gestegen $(4,5)$. Deze toenemende belangstelling laat een stijgend aantal publicaties op dit gebied zien (Figuur 1).

Gezien de groeiende belangstelling en het toenemende gebruik van botvervangende materialen zal in dit artikel ingegaan worden op de huidige stand van zaken met betrekking tot het gebruik van botvervangende materialen in de kliniek.

\section{Bottransplantatie}

Wereldwijd zijn er ongeveer 1 miljoen gevallen van botdefecten per jaar waarvoor opvulling nodig is voor herstel (6). Hierbij gaat het om botdefecten door trauma, bij posttraumatische complicaties als malunion en nonunion, en botdefecten als gevolg van het verwijderen van (congenitale) bottumoren (7). Er zijn vier soorten bottransplantaties mogelijk, een overzicht hiervan is weergegeven in Tabel 1(8).

De autogene bottransplantatie, waarbij het bot van de patiënt zelf wordt gebruikt, is de gouden standaard voor het opvullen van botdefecten. Hierbij wordt meestal een hoeveelheid bot uit de crista iliaca genomen, maar ook andere locaties in het lichaam zoals de tibiakop kunnen gebruikt worden als donorplaats (8). Alhoewel de cellulaire en biomechanische eigenschappen van het autogeen bot het meest optimaal zijn, is het gewenste klinische resultaat niet gegarandeerd. Het verkrijgen van het transplantaat verlengt de duur van de operatie, en de vorm van het transplantaat en de hoeveelheid ervan laten soms te wensen over. Bovendien treden in 8-39\% van de gevallen 
complicaties op, zoals chronische pijn op de plek waar het transplantaat verkregen is, zenuwbeschadiging, infectie, fractuur en secundaire instabiliteit. Ook kan het litteken van de donorplaats cosmetische problemen veroorzaken $(7,9,10)$. Een andere beperking is dat autogene bottransplantatie vaak niet kan worden uitgevoerd bij kinderen, ouderen en bij patiënten met een oncologische aandoening (7).

Isogene bottransplantatie is zelden mogelijk vanwege de lage incidentie van monzygote tweelingen (1 op 250 zwangerschappen) (11).

Bij allogene bottransplantatie zijn donor en recipiënt genetisch verschillend. Een duidelijk voordeel ten opzichte van de autogene bottransplantatie is de ruimere hoeveelheid beschikbaar botweefsel (8). Bovendien worden de complicaties vermeden die optreden bij het verkrijgen van het autogene bottransplantaat. Bij een allogene bottransplantatie wordt vaak gebruik gemaakt van de heupkop die verwijderd is bij het implanteren van een kunstheup. Een nadeel van allogene bottransplantatie ligt in zijn immunogene eigenschappen en in het risico op overdragen van contaminanten en pathologie zoals virale infecties (voornamelijk HIV en hepatitis B en C), bacteriële infecties, maligne aandoeningen, systemische ziekten (o.a. auto-immuunziekten) en toxines (7). Om deze risico's zoveel mogelijk te beperken wordt allogeen botweefsel voor gebruik diep gevroren, bestraald of chemisch behandeld. Echter door deze behandeling gaan voor een belangrijk deel de cellulaire en biomechanische eigenschappen verloren, hetgeen ongunstig is voor het bereiken van een klinisch goed resultaat. Bovendien kan ook na deze behandelingen antigeniciteit niet geheel uitgesloten worden $(7,8,12)$. Een ander allogeen transplantaat (soms onder de botvervangende materialen geschaard) is gedemineraliseerd bot matrix (DBM). Dit is gedecalcificeerd allogeen bot. Het materiaal behoudt door de bereiding (decalcificering) naast zijn matrix structuur ook een aantal groeifactoren en kan daardoor zelfs meer osteoinductief zijn dan allogeen bottransplantaat. Echter door verschil in bereidingsmethoden zijn de resultaten van DBM zeer wisselend (7, 12-14).

Bij xenogene bottransplantaties is het gebruikte donorbot van een dier afkomstig. Deze vorm van bottransplantaties wordt nog weinig toegepast vanwege de mogelijke immuunreactie bij de ontvanger en overdracht van pathologie (prionenoverdracht) (8). 


\section{Eigenschappen botvervangende materialen}

Omdat alternatieve bottransplantaties onvoldoende de problemen die kleven aan autogene bottransplantatie oplossen, is men gaan zoeken naar (synthetische) botvervangende materialen. Het ideale botvervangende materiaal is een product dat de cellulaire en biomechanische eigenschappen van het te vervangen bot zo goed mogelijk imiteert. Dit betekent dat het ideale materiaal osteogene, osteoinductieve en osteoconductieve eigenschappen heeft $(7,8,15)$.

Osteogenese is de aanmaak van bot. Hiervoor is donorbot nodig. Voorlopercellen in het transplantaat prolifereren en differentiëren tot osteoblasten en mogelijk tot osteocyten. Osteoinductie is het stimuleren en activeren van mesenchymale stamcellen in het weefsel rondom het botdefect, waardoor deze cellen vervolgens differentiëren tot botvormende osteoblasten. Dit proces wordt gemedieerd door een cascade van signalen en door de activatie van verscheidene extracellulaire en intracellulaire receptoren, met name van de transforming growth factor beta (TGF-beta) superfamilie.

Osteoconductiviteit houdt in dat de compositie, vorm, poriegrootte en oppervlakte van het materiaal als matrix voor botingroei en celmigratie functioneert. Naast deze drie kritische eigenschappen is het van belang dat het transplantaat goed hecht aan het bot van de ontvanger (osteointegratie) en dat het transplantaat bioresorbeerbaar is. Bioresorbeerbaar materiaal stimuleert botregeneratie. Dit houdt in dat tijdens de vorming van nieuw bot het materiaal geleidelijk wordt afgebroken (met behoud van sterkte door gelijktijdig nieuw botaanmaak). Daarnaast moet het botvervangende materiaal biocompatibel zijn, waardoor het geen immunologische reactie in het lichaam veroorzaakt. Bij het gebruik van het botvervangend materiaal treedt idealiter geen of slechts een minimale fibrotische reactie op $(12,14-17)$.

De hieronder beschreven, commercieel verkrijgbare, botvervangende materialen zijn niet osteogeen noch osteoinductief. Dit maakt deze osteoconductieve botvervangende materialen afhankelijk van het eigen regeneratief vermogen van bot.

\section{Botvervangende materialen}

Er is een grote verscheidenheid aan botvervangende materialen op de markt. In Nederland zijn 17 producten op de markt voor gebruik in botvervanging (peildatum 2007, Tabel 2). Alle producten hebben een eigen, unieke samenstelling en structuur. Er 
zijn veertien calciumfosfaten, twee calciumsulfaten en een bioactief glas. De kosten voor deze materialen zijn afhankelijk van het volume (2-20g) en variëren tussen $€ 150$ en $€ 800$.

Het klinische effect van botvervangende materialen hangt in sterke mate af van hun osteoconductiviteit. Deze wordt bepaald door een aantal eigenschappen, te weten poriegrootte, totaal poreus volume, onderlinge verbondenheid van poriën, mate van kristalliniteit, bioactiviteit en bioresorptie (18). De optimale poriegrootte ligt tussen de 150 en $500 \mu \mathrm{m}$ waarbij de poriën een grote onderlinge verbondenheid hebben. Een groter totaal poreus volume is gunstig voor botingroei, maar heeft als keerzijde een lagere mechanische stabiliteit. Natuurlijk bot heeft een microkristallijne structuur waardoor een groter oppervlakte van het materiaal ontstaat. Een microkristallijne structuur in botvervangend materiaal is mede bepalend voor de osteoconductiviteit. Bioactiviteit geeft door de chemische eigenschappen van het materiaaloppervlakte een aanhechting van het bot aan het botvervangende materiaal. De snelheid van botresorptie dient evenredig te zijn met de botaanmaak om mechanische stabiliteit te behouden (18). Een overzicht van de botvervangende materialen in relatie tot hun osteoconductieve eigenschappen is samengevat in Tabel 3.

Biologische materialen zijn in de natuur voorkomende materialen. Deze materialen voor botsubstitutie zijn collageen of biologisch calciumfosfaat keramiek (Tabel 2). Collageen kent van zichzelf goede matrix eigenschappen. Healos ${ }^{\circledR}$, een in Nederland verkrijgbaar (runder) collageen, is een botvervangend materiaal van collageen bedekt met hydroxyapatiet. Dit materiaal lijkt qua structuur op trabeculair bot. Tot biologisch calciumfosfaat behoren hydroxyapatiet keramieken verkregen uit dierlijk bot of koraal. Door de bereiding met zeer hoge temperaturen zijn eiwitten in het materiaal afgebroken waardoor het materiaal biocompatibel is (7).

Synthetische materialen zijn kunstmatig geproduceerde materialen. Deze bestaan voor het grootste deel uit calciumfosfaten, maar ook calciumsulfaat en bioactief glas behoren tot deze groep aan producten (Tabel 2). Doordat calciumfosfaten zowel in de geneeskunde als de agricultuur (mest), de farmacologie (tabletten en tandpasta) en de voedingsindustrie (voedingssupplementen) worden gebruikt, zijn ze uitgebreid onderzocht en is er veel over bekend (5). 
Er kunnen twee categorieën calciumfosfaten onderscheiden worden. Dit onderscheid wordt gemaakt op basis van de verschillende wijze van bereiding. De meeste calciumfosfaten worden bereid door een proces van sintering waarbij gebruik gemaakt wordt van zeer hoge temperaturen $\left(>1000^{\circ} \mathrm{C}\right)$. Calciumfosfaten die uit sintering ontstaan worden calciumfosfaat keramieken genoemd. Deze materialen resorberen zelden maar hebben een structuur van onderling verbonden poriën met een relatief grote maar wisselende porositeit $(4,5)$. De andere bereiding maakt gebruik van een chemisch proces van scheiding van calciumfosfaten uit een oplossing tot een vaste substantie. De calciumfosfaten die door deze bereiding ontstaan worden calciumfosfaat cementen genoemd. In deze cementen worden verschillende calciumfosfaten verwerkt, te weten alfatricalciumfosfaat, betatricalciumfosfaat, dicalciumfosfaat, moncalciumfosfaathydraat en tetracaliumfosfaat. Deze komen allemaal in natuurlijke vorm in het menselijk lichaam voor. Hoewel een grote verscheidenheid aan calciumfosfaten als basisstof gebruikt wordt, is het vaste eindproduct van alle calciumfosfaat cementen hydroxyapatiet of brushiet $(4,5)$. Calciumfosfaat cementen resorberen relatief snel maar hebben een lagere porositeit en kleinere poriën. Waar keramieken geleverd worden in blokken en granules, hebben alle cementen een pastaachtige substantie waardoor ze in elke vorm te modelleren zijn (4).

De biocompatibiliteit van calciumfosfaat keramieken en cementen is goed. De resorptie van apatiet calciumfosfaat cementen vindt plaats via osteoclasten activiteit en gaat sneller dan bij gesinterd hydroxyapatiet. Dit is verklaarbaar doordat het hydroxyapatiet eindproduct van calciumfosfaat cement andere eigenschappen heeft als gesinterd hydroxyapatiet. Een hydroxyapatiet cement heeft een meer microkristallijne structuur waardoor het oppervlakte gebied veel groter is. Oppervlaktes van $100 \mathrm{~m}^{2} / \mathrm{g}$ kunnen bereikt worden waar gesinterd hydroxyapatiet een oppervlakte heeft van circa 1 $\mathrm{m}^{2} / \mathrm{g}(4,5)$.

Bij klinische toepassingen zijn brushiet calciumfosfaat cementen vloeibaarder en beter injecteerbaar dan apatiet calciumfosfaat cementen. Brushiet calciumfosfaat cementen gedragen zich in vivo ook anders dan apatiet calciumfosfaat cementen. Waar de mechanische sterkte van apatiet calciumfosfaat cementen na implantatie alleen maar toeneemt, nemen de mechanische eigenschappen van brushiet calciumfosfaat cementen de eerste weken af totdat botingroei plaatsvindt. Op dat moment nemen de mechanische 
eigenschappen weer toe. Dit fenomeen is toe te schrijven aan de resorptie van brushiet calciumfosfaat cementen. Naast de resorptie door osteoclastische activiteit is brushiet calciumfosfaat oplosbaar waardoor de resorptie sneller verloopt $(4,19)$.

Een ander synthetisch botvervangend materiaal is calciumsulfaat (gips). Calciumsulfaat werd al in 1892 door Dreesman (Duitsland) gebruikt als botvervangend materiaal in botdefecten in de lange pijpbeenderen ontstaan door tuberculose (17). Calciumsulfaat resorbeert relatief snel (7).

Bioactief glas is een groep oppervlakte reactieve glas keramieken. Eind jaren zestig is het eerste bioactieve glas, BioGlass ${ }^{\circledR}$, door professor Hench ontwikkeld om Vietnam veteranen met ernstige botletsels te kunnen behandelen. De bioactiviteit en sterkte van het materiaal maken het materiaal geschikt om botdefecten te vullen, de stijfheid maakt het materiaal gevoelig voor fracturen bij buigkrachten (7).

\section{Ontwikkelingen}

Recente ontwikkelingen van botvervangende materialen richten zich met name op het verbeteren van de osteogene en osteoinductieve eigenschappen. Door toevoeging van beenmerg aspiraat vindt vanuit het botvervangende materiaal botregeneratie plaats. Door toevoeging van botinductie eiwitten, de 'bone morphogenetic protein' (BMP) uit de 'transforming growth factor beta' (TGF- $\beta$ ) familie wordt het materiaal osteoinductief. Naar beide therapeutische opties wordt verder onderzoek gedaan $(15,20)$.

Botvervangende materialen bieden een transportmogelijkheid voor lokale afgifte van antibiotica in geïnfecteerde botdefecten. Mogelijkheden om chemotherapeutica aan botvervangende materialen toe te voegen worden nog onderzocht (8).

\section{Klinisch gebruik}

Welk product voor welke indicatie gebruikt kan worden is niet altijd even duidelijk. Botvervangende materialen worden voor diverse indicaties gebruikt. Indicaties zijn met name fracturen van de tibia plateau, proximale tibia, calcaneus, pols, proximale humerus en distale radius. Figuur 2 toont een aantal röntgenfoto's met voorbeelden van gebruik van een botvervangend materiaal bij een tibia plateaufractuur respectievelijk een distale femurfractuur. In geval van mechanisch belastte botdefecten zal gekozen worden voor een mechanisch sterk product, bijvoorbeeld Calcibon ${ }^{\circledR}$, Cortoss $^{\circledR}$, Norian $^{\circledR}$ SRS of 
$\mathrm{MIIG}^{\circledR} \mathrm{X} 3$ (Tabel 2). Een andere praktische overweging voor indicatiestelling is dat kleinere botdefecten van bijvoorbeeld de handbeenderen vragen om een goed injecteerbaar botvervangend materiaal als ChronOS ${ }^{\circledR}$ Inject, Eurobone ${ }^{\circledR}$ of MIIG $^{\circledR}$ X3 . Daarnaast zal de keuze voor het botvervangende materiaal bepaald worden door informatie uit wetenschappelijk onderzoek en de ervaring van de chirurg.

Bovengenoemde materialen zijn osteoconductief, maar hebben geen osteoinductieve eigenschappen. Derhalve is gebruik ervan onvoldoende bij nonunion. 


\section{Literatuur}

1. Guthrie D. A history of medicine. Lonond: Nelson 1945.

2. Van Meekeren J. Heel- en geneeskunstige aenmerkingen. Casparus Commelijn 1668.

3. Donati D, Zolezzi C, Tomba P, Vigano A. Bone grafting: historical and conceptual review, starting with an old manuscript by Vittorio Putti. Acta Orthop 2007;78(1):19-25.

4. Bohner M. Calcium orthophosphates in medicine: from ceramics to calcium phosphate cements. Injury 2000;31 Suppl 4:37-47.

5. Bohner M, Gbureck U, Barralet JE. Technological issues for the development of more efficient calcium phosphate bone cements: a critical assessment. Biomaterials 2005;26(33):6423-9.

6. Salgado AJ, Coutinho OP, Reis RL. Bone tissue engineering: state of the art and future trends. Macromol Biosci 2004;4(8):743-65.

7. Giannoudis PV, Dinopoulos H, Tsiridis E. Bone substitutes: an update. Injury 2005;36 Suppl 3:S20-7.

8. Patka P, Haarman HJ, Bakker FC. [Bone transplantation and bone replacement materials]. Ned Tijdschr Geneeskd 1998;142(16):893-6.

9. Banwart JC, Asher MA, Hassanein RS. Iliac crest bone graft harvest donor site morbidity. A statistical evaluation. Spine 1995;20(9):1055-60.

10. Boone DW. Complications of iliac crest graft and bone grafting alternatives in foot and ankle surgery. Foot Ankle Clin 2003;8(1):1-14.

11. Braat DD, Schonbeck Y, Kremer JA. [Multiple pregnancies: epidemiology and management]. Ned Tijdschr Geneeskd 2003;147(40):1952-5.

12. Keating JF, McQueen MM. Substitutes for autologous bone graft in orthopaedic trauma. J Bone Joint Surg Br 2001;83(1):3-8.

13. Williams A, Szabo RM. Bone transplantation. Orthopedics 2004;27(5):488-95; quiz 496-7.

14. Bauer TW. An overview of the histology of skeletal substitute materials. Arch Pathol Lab Med 2007;131(2):217-24. 
15. De Long WG, Jr., Einhorn TA, Koval K, McKee M, Smith W, Sanders R, et al. Bone grafts and bone graft substitutes in orthopaedic trauma surgery. A critical analysis. J Bone Joint Surg Am 2007;89(3):649-58.

16. Beaman FD, Bancroft LW, Peterson JJ, Kransdorf MJ. Bone graft materials and synthetic substitutes. Radiol Clin North Am 2006;44(3):451-61.

17. Costantino PD, Friedman CD. Synthetic bone graft substitutes. Otolaryngol Clin North Am 1994;27(5):1037-74.

18. Blokhuis TJ, Termaat MF, den Boer FC, Patka P, Bakker FC, Haarman HJ. Properties of calcium phosphate ceramics in relation to their in vivo behavior. $\mathrm{J}$ Trauma 2000;48(1):179-86.

19. Charriere E, Terrazzoni S, Pittet C, Mordasini PH, Dutoit M, Lemaitre J, et al. Mechanical characterization of brushite and hydroxyapatite cements. Biomaterials 2001;22(21):2937-45.

20. Termaat MF, Den Boer FC, Bakker FC, Patka P, Haarman HJ. Bone morphogenetic proteins. Development and clinical efficacy in the treatment of fractures and bone defects. J Bone Joint Surg Am 2005;87(6):1367-78. 


\section{Legenda bij figuren}

Figuur 1. Aantal publicatievermeldingen voor 'bone substitute'in PubMed

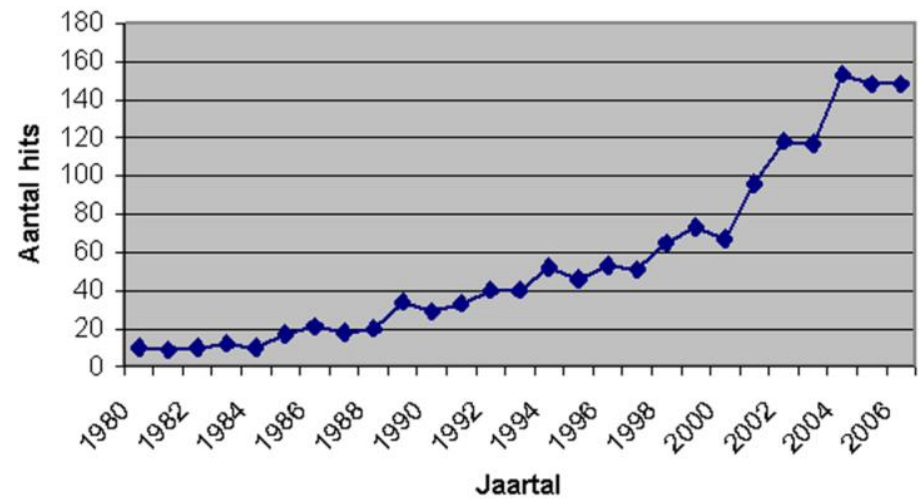

Figuur 2. Gebruik van een botvervangend materiaal bij een tibia plateaufractuur

(A) en een distale femurfractuur (B); anteroposterior opname aan

linkerzijde en laterale opname aan rechterzijde). Locatie van het

botvervangend materiaal is aangeduid met een witte pijl. In figuur B is tevens een hoekplaat gebruikt.
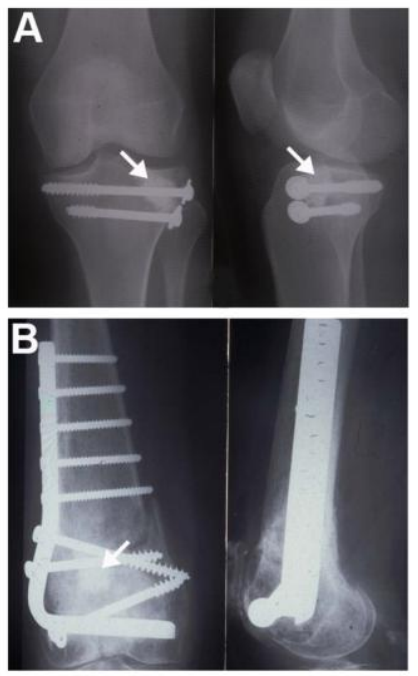